\title{
DESAIN DAN IMPLEMENTASI SISTEM KEAMANAN LOCKER MENGGUNAKAN E-KTP BERBASIS ARDUINO PRO MINI
}

\author{
Rizky Muhammad Syafii, Muhammad Ikhwanus, Misbahul Jannah \\ Jurusan Teknik Elektro, Fakultas Teknik Universitas Malikussaleh \\ Kampus Bukit indah, Jalan Batam No. 16 Kecamatan Blangpulo Lhokseumawe \\ E-mail : rizkymsyafii@gmail.com
}

\begin{abstract}
Abstrak - Pengamanan akses pribadi seperti yang diterapakan dalam penguncian locker umumnya hanya menerapkan sistem pengamanan manual mudah membobolnya. Sehingga dengan berkembangnya ilmu teknologi, dibuatlah sistem pengamanan akses pribadi yang menggunakan sistem elektronik dan lebih otomatis dengan tingkat kemanan lebih terjamin. Salah satu teknologi yang membantu perancangan sistem keamanan locker yang modren dan efisien adalah teknologi RFID (Radio Frequency Identification). RFID merupakan teknologi sistem pengindentifikasian suatu objek secara otomatis dengan cara mentransmisikan dan menerima data yang memanfaatkan dari frekuensi radio. Data yang ditransmisikan berupa kode informasi yang unik dan tidak bisa diduplikat sehingga lebih aman pengunaannya untuk locker. Secara ringkas, ada tiga komponen utama sistem RFID agar dapat bekerja mengidentifikasi suatu objek, yaitu tag RFID, Reader RFID dan Arduino Pro Mini sebagai pengendali sistem RFID. Hasil pengujian sistem ini mampu merekam lebih dari 2 pengguna locker yaitu sebanyak 15 pengguna locker dengan jarak baca efektif untuk tag jenis key chain dengan tingkat keberhasilan $100 \%$ jarak bacanya $\leq 2,5 \mathrm{~cm}$ dan e-KTP jarak baca efektif dengan tingkat keberhasilan $100 \%$ berjarak $\leq 3,5 \mathrm{~cm}$, untuk jenis tag RFID white card dengan tingkat keberhasilan $100 \%$ jarak baca $\leq 5$ cm, tag white card merupakan jarak baca paling terjauh diantara e-KTP dan key chain sesuai dengan data sheet reader RFID $R C 522$.
\end{abstract}

Keywords - RFID, e-KTP, locker, Arduino Pro Mini

\section{PENDAHULUAN}

Dalam perkembangan dunia teknologi semakin maju maka diperlukan kesadaran kita untuk berusaha menerapkan teknologi tepat guna yang dapat bermanfaat bagi kehidupan masyarakat. Dengan penerapan teknologi sains khususnya dalam ilmu teknik elektro, dapat membantu memudahkan masyarakat dalam melakukan suatu pekerjaan, tak terkecuali dalam hal pengamanan barang pada locker.

Pengamanan akses pribadi seperti yang diterapakan dalam penguncian locker umumnya hanya menerapkan sistem pengamanan manual dan mudah untuk dapat membobolnya. Sehingga dengan berkembangnya ilmu teknologi, maka dibuatlah suatu sistem pengamanan akses pribadi yang menggunakan sistem elektronik dan lebih otomatis dengan tingkat kemanan lebih terjamin. Salah satu teknologi yang membantu perancangan sistem keamanan locker yang modren dan efisien adalah teknologi RFID (Radio Frequency Identification).

Radio Frequency Identification (RFID) merupakan salah satu teknologi dari sistem pengindentifikasian suatu objek secara otomatis dengan cara mentransmisikan dan menerima data yang memanfaatkan dari frekuensi radio. Data yang ditransmisikan berupa kode informasi yang unik dan tidak bisa diduplikat sehingga lebih aman pengunaannya.

Di samping hal tersebut, pada February 2011 Kementerian Dalam Negeri Republik Indonesia mengusulkan program baru yaitu program pengantian kartu tanda penduduk yang konvensional ke kartu tanda penduduk elektronik atau electronic-KTP ( $e$-KTP), Keungulan $e$-Ktp dari KTP yang konvensional adalah $e$-KTP memiliki teknologi RFID didalamnya..

\section{DASAR TEORI}

\subsection{Radio Frequency Identification (RFID)}

Radio Frequency Identification atau yang lebih dikenal sebagai RFID merupakan suatu metoda identifikasi objek yang menggunakan gelombang radio. Proses identifikasi dilakukan oleh reader RFID dan RFID transponder (RFID Tag). Tag RFID dilekatkan pada suatu benda atau suatu objek yang akan diidentifikasi. Tiap-tiap RFID tag memiliki data angka identifikasi (ID number) yang unik, sehingga tidak ada tag RFID yang memiliki ID number yang sama.

RFID digunakan untuk mendeskripsikan sebuah sistem yang mampu untuk mengirimkan data identitas sebuah objek secara nirkabel dengan menggunakan gelombang radio. RFID termasuk kedalam teknologi Automatic Identification (Auto-ID). Saat ini sistem identifikasi otomatis tersebut menjadi sangat populer dalam berbagai macam industri seperti jasa, pembelian, manufactur dan lain sebagainya. Teknologi lain yang termasuk dalam Auto-ID adalah barcode, pembaca karakter optis dan teknologi biometri.

Label barcode yang ada dimana-mana merupakan pencetus revolusi sistem identifikasi otomatis. Meskipun barcode sangat murah namun terdapat kelemahan dalam segi kapasistas penyimpanannya yang rendah dan tidak adanya kemampuan untuk diprogram ulang. Solusi optimal secara teknis adalah dengan memanfaatkan sebuah silicon chip 
sebagai media penyimpanan yang kemudian diadopsi dalam sistem RFID[1].

\section{Sistem RFID}

Sebuah sistem RFID menggunakan teknologi komunikasi radio tanpa kabel untuk mengidentifikasi suatu objek . Ada tiga komponen dasar agar sistem RFID dapat bekerja, seperti yang ditunjukkan pada Gambar 2.1 [2]:

1. Tag RFID (transponder) yang terdiri dari chip berbahan semikonduktor, antena dan terkadangt Tag mengunakan baterai.

2. Reader RFID: sebuah modul elektronik dan dilengkapi dengan antena untuk membaca data Tag RFID.

Sebuah Pengendali (sebagai host) : yang menjalankan sistem kontrol RFID.

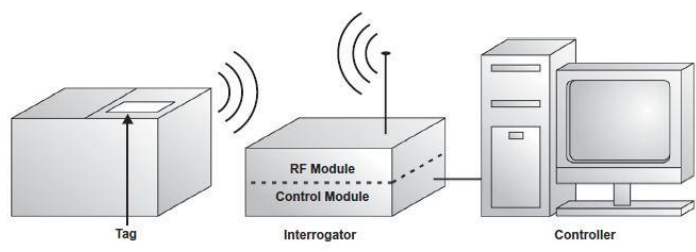

Gambar 2.1 Blog Dasar Sistem RFID[2]

\section{Tag RFID}

Fungsi dasar dari sebuah tag RFID adalah untuk menyimpan data dan mengirimkan data ke reader RFID. Pada dasarnya, tag terdiri dari chip elektronik dan antena (lihat Gambar 2-2) yang dikemas dalam satu paket untuk membentuk tag atau label kemasan. Umumnya, chip berisi data informasi yang disimpan didalam memori pada chip tersebut. Tag RFID terbagi atas dua yaitu[3]:

1. Tag Aktif : memancarkan sinyal dengan tenaga dari baterai. Pada umumnya RFID tidak memancarkan sinyal terus menerus. Untuk menghemat baterai, RFID hanya akan memancarkan sinyalnya apabila ada sinyal pemicu yang sesuai dengan tata cara pengiriman dan penerimaannya. Sinyal pemicu ini biasanya ditempatkan menjadi satu pada alat pemancar atau penerima (Reader / Antena).

2. Tag Pasif : Tag ini tidak mempunyai baterai. Sinyal dikirim oleh reader/antena diterima oleh tag RFID, kemudian rangkaian dalam tag dengan menggunakan energi sinyal tersebut mengirim data ke antena/Reader kembali. Oleh karena itu sinyal tersebut lemah jarak jangkauannya.

Salah satu bentuk dari tag pasif adalah kartu tanda penduduk elektronik atau electronic-KTP (e-KTP). Kartu Tanda Penduduk (KTP) yang dibuat secara elektronik, dalam artian baik dari segi fisik maupun penggunaannya berfungsi secara komputerisasi.

$e$-KTP mengacu pada standar ISO $14443 \mathrm{~A} / \mathrm{B}$ bekerja dengan baik pada kisaran suhu antara $-250 \mathrm{C}$ sampai dengan $70 \mathrm{oC}$ dan dengan kisaran frekuensi operasional 13,56 MHz \pm 7 KHz. e-KTP mempunyai SAM (Secure Access Module) berupa 4 bytes UIDs (Unique identifier) dalam range kombinasi 10 digit[4].

\section{Kelebihan e-KTP Sebagai Tag Pasif}

Bahan fisik chip yang tipis seperti kertas didominasi oleh silikon dan jenis plastik, tidak tahan panas, korosi, basah atau lembab. Chip e-KTP menggunakan antar muka nirsentuh (contactless) yang memenuhi standar ISO 14443 A/B[5]. Transmisi data melalui gelombang radio. Blangko $e$-KTP terbuat dari bahan PETG, semacam polimer termoplastik, yang tersusun dalam 7 lapisan.

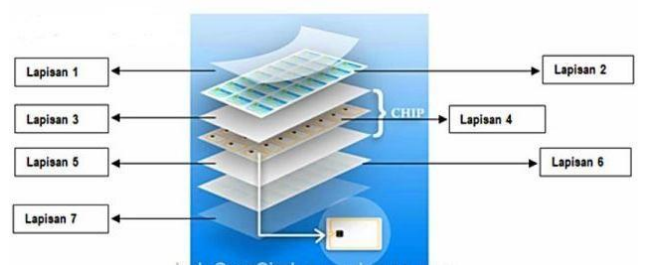

Gambar 2.2 lapisan e-KTP

Bahan fisik chip yang tipis seperti kertas didominasi oleh silikon dan jenis plastik, tidak tahan panas, korosi, basah atau lembab serta dapat rusak akibat patah, sobek dan jenis pengrusakan fisik lainnya. $e$-KTP sendiri secara mekanisme teknis memilikikeuntungan:

1. Chip e-KTP dilindungi, salah satunya, dengan mekanisme autentikasi dua arah, yaitu suatu mekanisme untuk saling mengenali antara chip e-KTP dengan reader RFID, di mana chip harus dapat mengenali reader RFID (arah 1) dan reader RFID harus dapat mengenali chip (arah 2), setelah melalui mekanisme autentikasi ini maka data yang tersimpan di dalam chip baru dapat dibaca oleh reader RFID.

2. Reader RFID harus menghasilkan medan radio frekuensi tinggi untuk memberikan pasokan daya yang sesuai dengan kebutuhan chip e-KTP, di mana medan medan radio tersebut akan dimodulasikan untuk keperluan komunikasi.

3. Kisaran dari besar medan magnet frekuensi radio yang dihasilkan oleh reader RFID adalah mengikuti ketentuan dalam ISO/IEC 14443, yaitu antara 1,5 A/m sampai dengan 7,5 A/m. Sedangkan besar frekuensi dari modulasi amplitudo medan magnet tersebut, yang digunakan untuk mengirimkan data ke chip e-KTP, adalah $13,56 \mathrm{MHz}[6]$.

4. Chip yang tertanam dalam kartu ini memungkinnya melakukan berbagai proses komputasi yang tidak dapat dilakukan oleh kartu berbasis magnetic stripe. Dengan kemampuan ini, kartu chip dapat menjalankan berbagai algoritma dan protokol keamanan yang cukup kompleks.

\section{Reader MIFARE RC522 RFID}

Reader RFID adalah merupakan penghubung antara software aplikasi dengan antena yang akan meradiasikan gelombang radio ke tag RFID. Gelombang radio yang ditransmisikan oleh antena berpropagasi pada ruangan di 
sekitarnya. Akibatnya data dapat berpindah secara wireless ke tag RFID yang berada berdekatan dengan antena.

Salah satu reader RFID untuk mendeteksi kode RFID pada $e$-KTP adalah Reader MIFARE RC522, Reader ini khusus mendeteksi Tag RFID dengan frekuensi $13.35 \mathrm{kHz}$. Reader RFID yang kompatibel dengan $e$-KTP dikarenkan keduannya mengunakan standar ISO ISO 14443 A/B.

MIFARE RC522 RFID Reader Module adalah sebuah modul berbasis IC Philips MFRC522 yang dapat membaca RFID dengan penggunaan yang mudah dan harga yang murah, karena modul ini sudah berisi komponen-komponen yang diperlukan oleh MFRC522 untuk dapat bekerja Modul ini dapat digunakan langsung oleh MCU dengan menggunakan interface SPI, dengan suplai tegangan sebesar 3,3 Volt DC.

MFRC522 merupakan produk dari NXP yang menggunakan fully integrated $13.56 \mathrm{MHz}$ non-contact communication card chip untuk melakukan pembacaan maupun penulisan. MFRC522 cocok dengan semua varian MIFARE Mini, MIFARE 1K, MIFARE 4K, MIFARE Ultralight, MIFARE DESFire EV1and MIFARE Plus RF identification protocols[7].

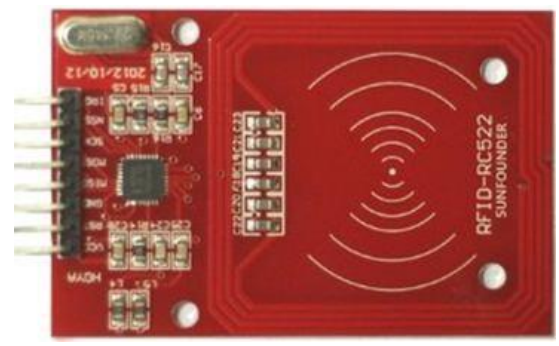

Gambar 2.3 Bentuk fisik modul reader MFRC522 RFID. [7]

Spesifikasi dari modul Reader RFID MIFARE RC522

1. Chipset : MFRC522 Contactless Reader/Writer IC.

2. Frekuensi : $13,56 \mathrm{MHz}$.

3. Jarak pembacaan kartu : $<=50 \mathrm{~mm}$.

4. Protokol akses : SPI (Serial Peripheral Interface) @ 10 Mbps.

5. Kecepatan transmisi RF : 424 kbps (dua arah / bidirectional) / 848 kbps (unidirectional).

6. Mendukung kartu MIFARE jenis Classic S50 / S70, Ultra Light, dan DESFire.

7. Catu Daya : 3,3 Volt DC.

8. Konsumsi Arus : 13-26 mA pada saat operasi baca/tulis, $<80 \mu A$ saat modus siaga.

9. Suhu operasional : $-20^{\circ} \mathrm{C}$ s.d. $+80^{\circ} \mathrm{C}$

10. Dimensi : $40 \times 50 \mathrm{~mm}$

\section{Sistem Kontrol RFID}

Sistem Kontrol RFID adalah sebagai sistem pengendalian untuk mengakses secara elektronik untuk memecahkan keterbatasan pada kunci mekanik yang bekerja secara konvensional. Berbagai macam hak akses dapat digunakan untuk menggantikan kunci mekanik.

Misalnya Ketika untuk mengakses sebuah pintu, jika akses untuk membuka pintu disetujui maka pintu akan terbuka pada waktu yang telah ditentukan secara automatis dan transaksi tersebut akan dicatat oleh sistem. Ketika akses ditolak, pintu akan tetap terkunci dan usaha untuk mengakses tersebut juga akan dicatat. Sistem ini juga dapat membunyikan alarm jika pintu salah diakses.

\section{Frekuensi Kerja RFID}

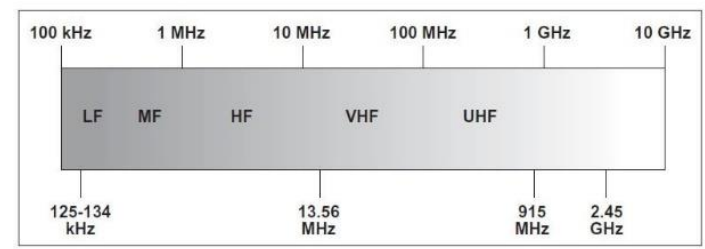

Gambar 2.4 Frekuensi RFID

Radio frekuensi yang digunakan oleh tag untuk mengirim dan menerima sinyal memiliki implikasi pada performa, jarak, operasi, kecepatan baca tag dan data RFID frekuensi yang digunakan oleh system RFID dibuat ada 4 macam[8]:

1. Band LF (Low Frequensi) dengan rentang frekuensi $125 \mathrm{KHz}$ - $134 \mathrm{KHz}$ dengan penggunaan jarak pendek, kurang lebih $50 \mathrm{~cm}$. biasanya dipergunakan untuk system identifikasi yang hanya membutuhkan jarak pendek.

2. Band HW (High Frequensi) yang beroperasi pada frekuensi $13.56 \mathrm{KHz}$ dengan pembacaanya hingga kurang lebih $3 \mathrm{~m}$, pada frekuensi ini cocok digunakan untuk pembacaan pada tag RFID dan banyak juga digunakan untuk pencocokan barang-barang di gudang-gudang industri, gedung atau pelacakan yang memerlukan dengan kecepatan baca 10 hingga 100 Tag RFID / detik.

3. Band UHF (Ultra High Frequensi) sekitar $915 \mathrm{MHz}$ dengan rentang pembacaan hingga sekitar $9 \mathrm{~m}$. Tag UHF dapat dibaca dengan kecepatan hingga 1000 Tag/detik. Biasanya banyak dipergunakan untuk pelacakan barang pada kontainer truk.

4. Gelombang mikro 2,4 GHz dengan jarak pembacaan yang jarak lebih jauh $(10 \mathrm{~m})$ pada frekuensi ini lebih banyak mengalami pantulan gelombang dan objek disekitarnya dan dapat mengagu kemampuan reader RFID untuk komunikasi dengan tag RFID

\section{Tingkat Akurasi Sistem RFID}

Tingkat akurasi RFID didefinisikan sebagai tingkat keberhasilan reader RFID melakukan identifikasi sebuah tag yang berada pada area kerjanya. Keberhasilan dari proses identifikasi sangat dipengaruhi oleh beberapa batasan fisik, yaitu[9] :

1. Posisi antena pada reader RFID.

2. Karakteristik dari material lingkungan yang mencakup sistem RFID.

3. Batasan catu daya.

4. Frekuensi kerja sistem RFID.

\section{Arduino}

Arduino adalah kit elektonik atau papan rangkaian elektronik open source yang didalamnya terdapat komponen utama yaitu sebuah chip mikrokontroler dengan jenis AVR 
dari perusahaan Atmel. Mikrokontroler itu sendiri adalah chip atau IC (Integrated Circuit) yang bisa diprogram menggunakan komputer.

Tujuan menanamkan program pada mikrokontroler adalah agar rangkaian elekronik dapat memberikan input, memproses input tersebut dan kemudian menghasilkan output sesuai yang diinginkan. Jadi mikrokontroler bertugas sebagai 'otak' yang mengendalikan input dan output sebuah rangkaian elektronik. Secara umum, Arduino terdiri dari dua bagaian, yaitu :

1. Hardware berupa papan input/output (I/O) yang open source.

2. Software Arduino yang juga open source, meliputi software Arduino IDE untuk menulis program di komputer selanjutnya ditransfer ke Arduino.

\section{METODOLOGI}

\section{Diagram Alir Sistem Kerja}

Sebelum membuat program dibutuhkan pemahaman urutan kerja dari alat yang akan dibuat, sehingga program yang dibuat bisa berurutan sesuai yang diinginkan. Untuk lebih mudah membuat programnya terlebih dahulu merancang diagram alir sistem kerja keamanan locker, berikut ini diagram alirnya

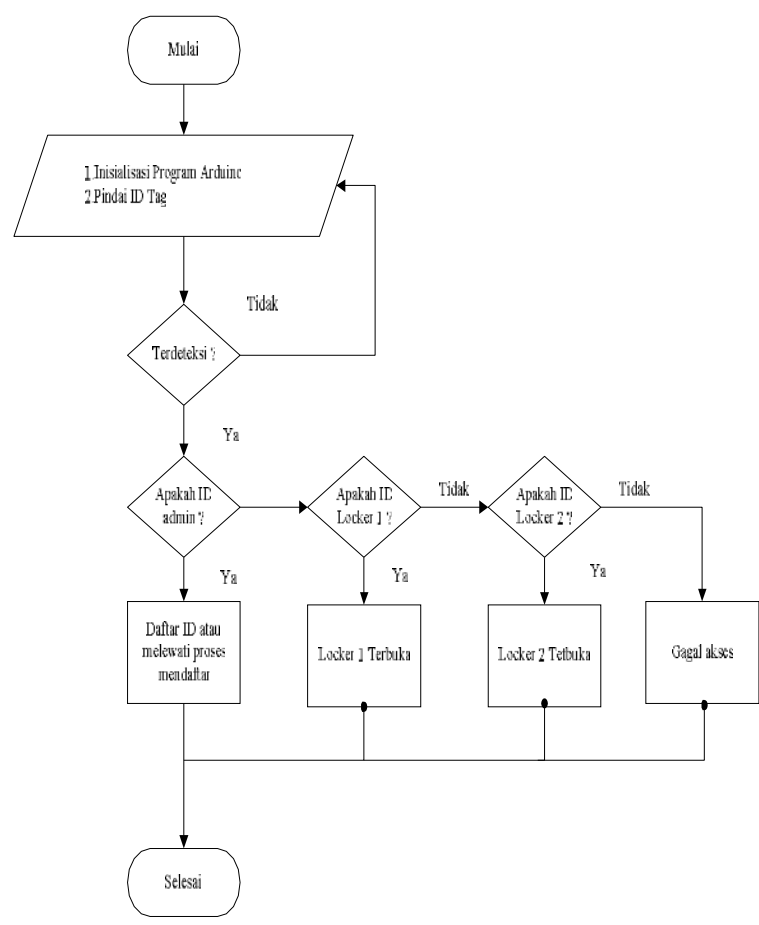

Gambar 3.1 Diagram alir sistem Kerja sistem keamanan locker

Penjelasan diagram alir sistem kerja program sistem keamanan locker:

1. Mulai : Langkah pertama untuk mengoperasikan alat yaitu dengan memberikan tegangan pada sistem atau rangkaian.

2. Inisialisasi Arduino Pro Mini : Setelah sistem aktif Arduino Pro Mini akan melakukan fungsinya sebagai kontrol dari semua input dan output. Arduino Pro Mini mengaktifkan reader RFID dan LCD. Setelah aktif, LCD akan menampilkan tulisan untuk menempelkan $e$-KTP.

3. Scane e-KTP ke Reader RFID : Reader RFID akan membaca data pada $e$ - KTP melalui pancaran gelombang elektromagnetik. Data yang dibaca oleh reader RFID akan diteruskan ke Arduino Pro Mini untuk divalidasi dengan penyesuaian ID yang terdaftar pada memori Arduino Pro Mini.

4. Apabila data yang dikirim oleh reader RFID terdaftar, Arduino Pro Mini akan menjalankan instruksi selanjutnya yaitu mendaftarkan kode $e$-KTP yang ingin didaftar atau melewati proses pendaftaran. Jika kode $e$-KTP sesuai dengan di memori eeprom arduino maka arduino akan mengaktifkan Indikator LED hijau, buzzer, driver relai dan solenoid sehingga locker akan terbuka sesuai dengan kode locker 1 atau locker 2 yang telah didaftarkan.

5. Solenoid off Setelah 10 detik maka Arduino Pro Mini akan memberikan intruksi kepada relai untuk aktif low dan solenoid (Off) pengunci akan tertutup.

6. Apabila $e$-KTP yang ditempelkan tidak terdaftar pada memori, maka LED merah menyala dan buzzer akan berbunyi, sebagai tanda bahwa $e$-KTP yang ditempelkan tidak dikenali

7. Selesai : Semua proses penguncian dan pembukaan akan kembali ke posisi inisialisasi ATmega 328 (Looping).

\section{Diagram Blok}

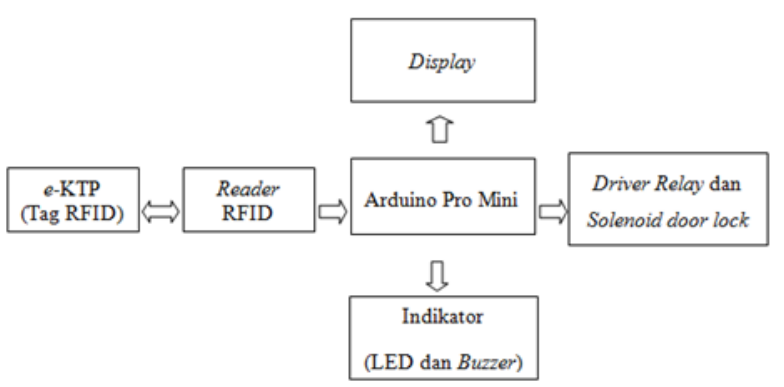

Gambar 3.2 Diagram Blok sistem keamanan locker

Dari gambar 3.2 dapat dilihat beberapa hubungan antar bagian dalam sistem aplikasi radio frequency identification pada keamanan locker. Dari gambar 3.2, Arduino Pro Mini merupakan bagian utama yang berfungsi sebagai pengendali utama CPU (Central Processing Unit).

Tag RFID dan reader RFID (pembaca tag RFID) Sebagai masukan atau input data ke Arduino Pro Mini yang selanjutanya data tersebut akan diolah untuk akses sebuah locker. Sedangkan keluaran atau output sistem yaitu tampilan LCD (Liquid Crystal Display), LED, Buzzer dan sebuah solenoid sebagai kunci digital elektronik. Dalam tugas akhir ini akan dijelaskan satu per satu bagian sistem keamanan locker dengan teknologi Radio Frequency Identification (RFID). 


\section{Rangkaian Arduino Pro Mini}

Rangkaian ini berfungsi sebagai pusat kendali dari seluruh sistem yang ada. Rangkaian tersebut sudah menjadi satu modul dengan IC regulator untuk catu daya arduino dan IC untuk komunikasi antar arduino pro mini ke PC. Komponen utama dari rangkaian keseluruhan ini adalah IC mikrokontroler ATMega 328. Pada IC inilah semua program diisikan, sehingga rangkaian dapat berjalan sesuai dengan yang dikehendaki.
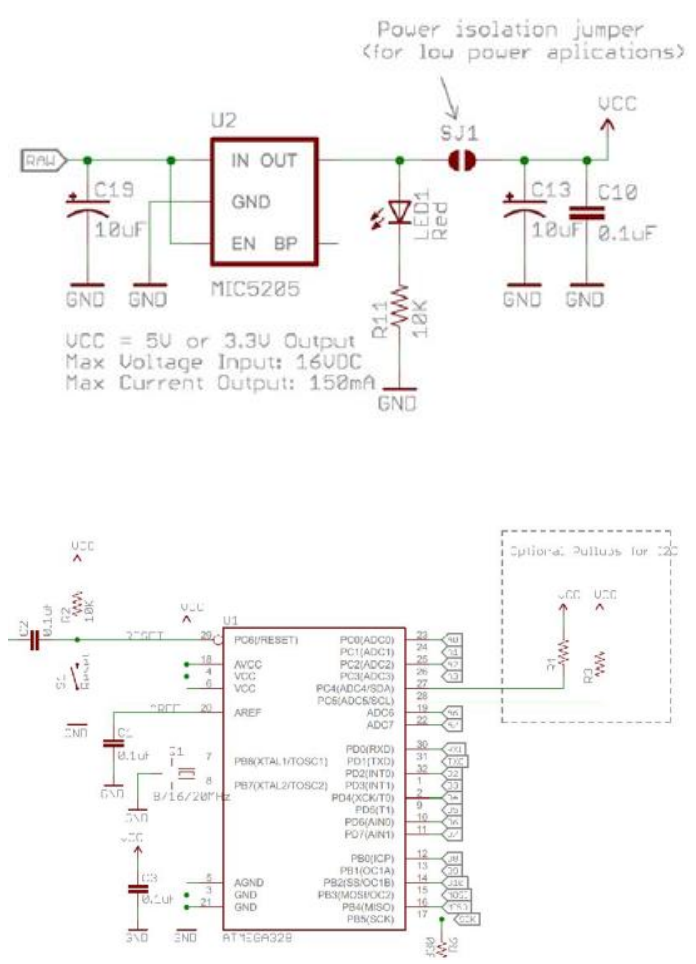

Gambar 3.3. Sistem Minimum Arduino Pro Mini

\section{Rangkaian Modul Reader RFID}

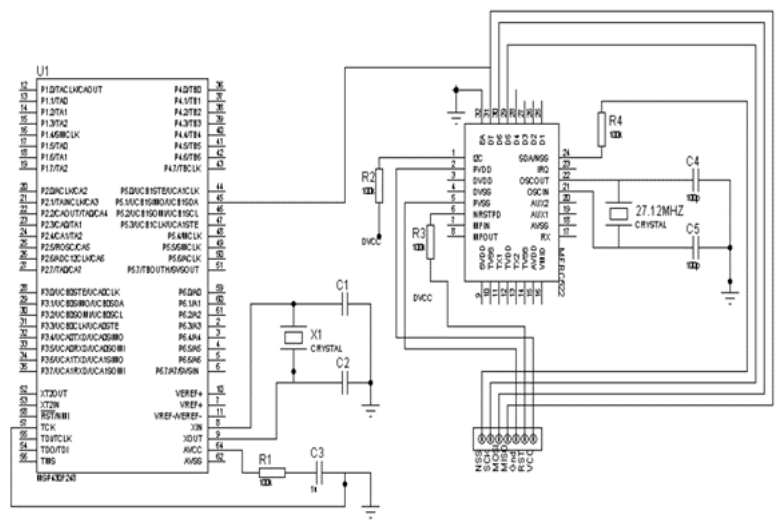

Gambar 3.4 Schematic Modul Reader RFID RC522

Modul reader RFID reader ini berfungsi untuk membaca data atau nomor ID pada $e$-KTP yang kemudian mengirim data tersebut ke Arduino Pro Mini. Pemasangan komponen modul reader RFID dengan port Arduino Pro Mini dapat dilihat pada tabel 3.2 dan tabel 3.3

Tabel 3.1 Speksifikasi Modul Reader RFID

\begin{tabular}{|l|l|l|}
\hline No & \multicolumn{1}{|c|}{ Parameter } & \multicolumn{1}{|c|}{ Deskripsi } \\
\hline 1 & Supports Card & ISO/IEC14443A/MIFARE \\
\hline 2 & Frequency & $13.56 \mathrm{MHz}$ \\
\hline 3 & VDDA (Tegangan Kerja) & $2.5-3.6$ Volt \\
\hline 4 & IDDA (Arus Kerja) & $10 \mathrm{Ma}$ \\
\hline
\end{tabular}

Tabel 3.2 Sambungan Pin Reader RFID Ke Arduino Promini

\begin{tabular}{|l|l|l|}
\hline No & Nam & \multicolumn{1}{c|}{ Pin Arduino Pro Mini } \\
\hline 1 & NSS & Digital Pin 10 \\
\hline 2 & MOSI & Digital Pin 11 \\
\hline 3 & MISO & Digital Pin 12 \\
\hline 4 & SCK & Digital Pin 13 \\
\hline 5 & RST & Digital Pin 9 \\
\hline 6 & GND & GND \\
\hline 7 & VCC & 3.3 Volt DC \\
\hline
\end{tabular}

Reader RFID akan mengeluarkan gelombang radio dan menginduksi tag RFID, Jika reader kompatible dengan tag RFID, maka memori tag RFID akan mengirimkan kode yang terdapat di memori ID chip melalui antena yang terpasang di tag RFID ke reader RFID. Selanjutnya reader RFID akan meneruskan kode yang diterima ke Arduino Pro Mini.

Arduino Pro Mini akan melaksanakan instruksi yang telah diberikan, jika kode tersebut sesuai maka otomatis akan mengaktifkan relai sehingga solenoid aktif dan membuka pintu, namun jika kode atau nomer ID tidak sesuai maka relai tidak aktif solenoid akan (Off) dan pintu tidak terbuka.

\section{HASIL DAN PEMBAHASAN}

\section{Pengujian RFID}

Dalam tugas akhir ini sample untuk pengujian mengunakan 4 buah $e$-KTP, dari keempat tersebut 3 buah $e$ KTP sebagai calon pengguna, 1 buah $e$-KTP sebagai admin yang berfungsi untuk mendaftar dan menghapus pengguna locker pada eeprom arduino agar tidak merubah struktur bahasa program arduinonya Sehingga locker bekerja secara efisien.

Setelah itu diuji dengan diberi gangguan akses dari luar sistem yaitu dengan mengakses locker dengan jenis tag RFID lain yang frekuensinya sama dan membandingkan hasil pengujian keseluruhan tersebut. Adapun jenis tag RFID lain yang frekuensinya sama yaitu jenis tag RFID white card dan key chain. Sample Tag RFID untuk pengujian ditunjukan pada tabel 4.1 dibawah ini. 
Tabel 4.1 Sample Tag RFID untuk pengujian

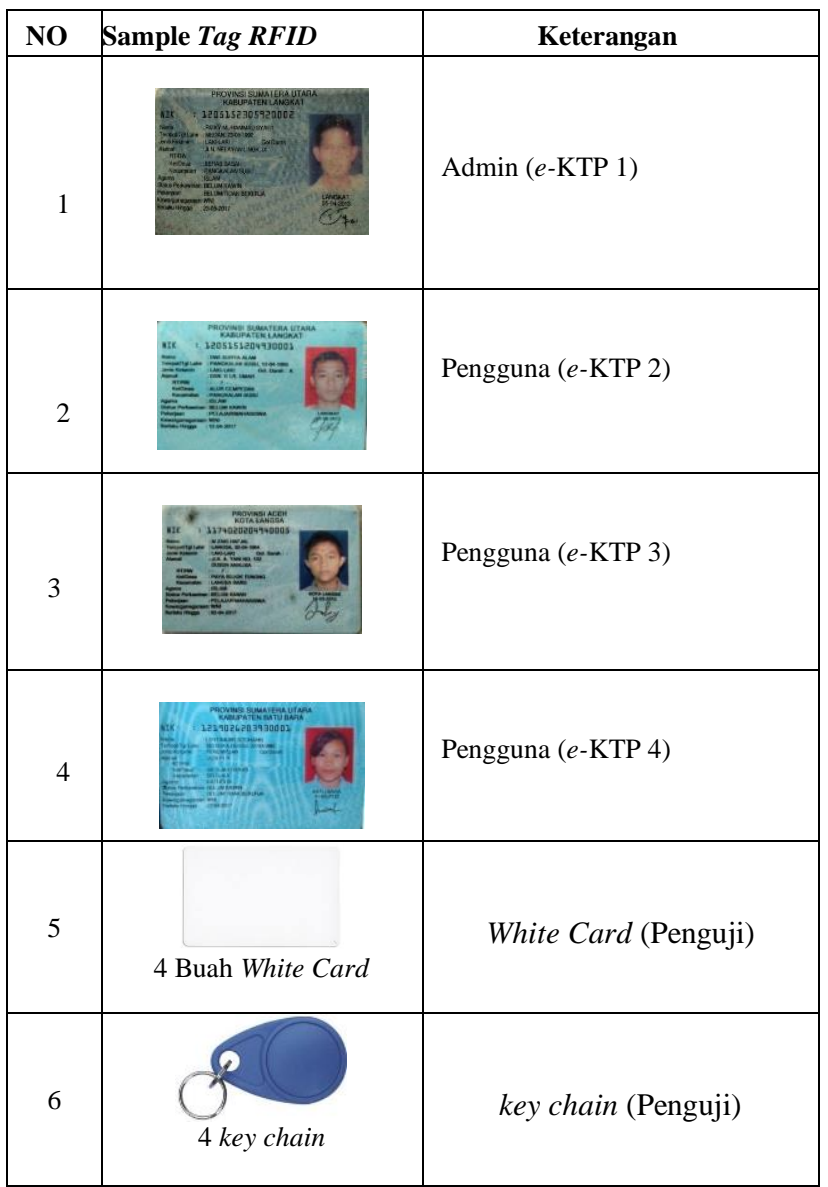

\section{Hasil Pembacaan Kode Tag RFID}

Pengujian ini dilakuan dengan mengunakan reader RFID RC522, 4 buah e-KTP, 4 buah tag jenis white card dan 4 buah tag jenis key chain untuk menguji data dan membandingkan data tersebut apakah data dari RFID reader dapat membaca informasi atau tidak. Selanjutnya data terebut diolah di arduino. Data hasil Pengujian modul RFID ditunjukkan dalam Tabel 4.2 dibawah ini.

Tabel 4.2. Hasil Pembacaan Kode Tag RFID

\begin{tabular}{|c|c|c|}
\hline No & Kode RFID $\boldsymbol{e}$-KTP & Tag RFID \\
\hline 1 & 1650010752 & $e$-KTP 1 \\
\hline 2 & 3797426816 & $e$-KTP 2 \\
\hline 3 & 2186684032 & $e$-KTP 3 \\
\hline 4 & 2051680384 & $e$-KTP 4 \\
\hline 5 & 1421859169 & White Card 1 \\
\hline 6 & 0857871659 & White Card 2 \\
\hline 7 & 1492022987 & White Card 3 \\
\hline 8 & 1411829431 & White Card 4 \\
\hline 9 & 3831985575 & key chain 1 \\
\hline 10 & 2760842134 & key chain 2 \\
\hline 11 & 0820798654 & key chain 3 \\
\hline 12 & 1281159712 & key chain 4 \\
\hline
\end{tabular}

\section{Jarak Pembacaan Tag RFID}

Dari hasil pengujian tabel 4.3 dapat diamati kode tag yang terdeteksi oleh reader merupakan kode dari e-KTP yang terdeteksi. Pengujian berikutnya adalah pengujian jarak membaca data antara reader dan e-KTP yang bertujuan untuk mengetahui jarak terjatuh kemampuan reader mendeteksi keberadaan e-KTP sejauh mana kemampuan reader mentransmisikan data.

Perhitungan analisis nilai persentase keberhasilan pada pengukuran jarak jangkauan pembacaan RFID dilakukan dengan cara membandingkan selisih antara hasil alat pengukuran dan nilai pada teori yang ditetapkan (nominal). Maka dari itu nilai tetapan jarak jangkauan diambil dari kemampuan reader $R F I D$ untuk mentransmisikan data ke setiap tag RFID yang kompatible terhadapnya yaitu $\leq 5 \mathrm{~cm}$ jarak jangkauannya. Berikut hasil pencarian persentase keberhasilan yang telah diuji dari proses pengujian $e$-KTP terhadap reader. menggunakan persamaan(2.10). Tabel 4.3. Hasil Pengujian Driver Relay

\begin{tabular}{|c|c|c|c|c|c|c|c|c|c|c|c|c|}
\hline \multirow[t]{2}{*}{ No } & \multirow[t]{2}{*}{ Tag RFID } & \multicolumn{10}{|c|}{ Jarak (cm) } & \multirow{2}{*}{$\begin{array}{c}\text { Persentase } \\
\text { Keberhasilan }\end{array}$} \\
\hline & & 1 & 1,5 & 2 & 2,5 & 3 & 3,5 & 4 & 4,5 & 5 & 5,5 & \\
\hline 1 & $e$-KTP 1 & $\sqrt{ }$ & $\sqrt{ }$ & $\sqrt{ }$ & $\sqrt{ }$ & $\sqrt{ }$ & $\sqrt{ }$ & $\mathbf{X}$ & $\mathbf{X}$ & $\bar{X}$ & $\mathbf{X}$ & $70 \%$ \\
\hline 2 & $e$-KTP 2 & $\sqrt{ }$ & $\sqrt{ }$ & $\sqrt{ }$ & $\sqrt{ }$ & $\sqrt{ }$ & $\sqrt{ }$ & $\mathbf{X}$ & $\mathbf{X}$ & $\mathbf{X}$ & $\mathbf{X}$ & $70 \%$ \\
\hline 3 & $e$-KTP 3 & $\sqrt{ }$ & $\sqrt{ }$ & $\sqrt{ }$ & $\sqrt{ }$ & $\sqrt{ }$ & $\sqrt{ }$ & $\mathbf{x}$ & $\mathbf{X}$ & $\mathbf{X}$ & $\mathbf{x}$ & $70 \%$ \\
\hline 4 & $e$-KTP 4 & $\sqrt{ }$ & $\sqrt{ }$ & $\sqrt{1}$ & $\sqrt{1}$ & $\sqrt{ }$ & $\sqrt{ }$ & $\mathbf{X}$ & $\mathbf{X}$ & $\mathbf{X}$ & $\mathbf{X}$ & $70 \%$ \\
\hline 5 & White Card 1 & $\sqrt{ }$ & $\sqrt{ }$ & $\sqrt{ }$ & $\sqrt{ }$ & $\sqrt{ }$ & $\sqrt{ }$ & $\sqrt{ }$ & $\sqrt{ }$ & $\sqrt{ }$ & $\mathbf{x}$ & $100 \%$ \\
\hline 6 & White Card 2 & $\sqrt{ }$ & $\sqrt{ }$ & $\sqrt{ }$ & $\sqrt{ }$ & $\sqrt{ }$ & $\sqrt{ }$ & $\sqrt{ }$ & $\sqrt{ }$ & $\sqrt{ }$ & $\mathbf{X}$ & $100 \%$ \\
\hline 7 & White Card 3 & $\sqrt{ }$ & $\sqrt{ }$ & $\sqrt{ }$ & $\sqrt{ }$ & $\sqrt{ }$ & $\sqrt{ }$ & $\sqrt{ }$ & $\sqrt{ }$ & $\sqrt{ }$ & $\mathbf{X}$ & $100 \%$ \\
\hline 8 & White Card 4 & $\sqrt{ }$ & $\sqrt{ }$ & $\sqrt{ }$ & $\sqrt{ }$ & $\sqrt{ }$ & $\sqrt{ }$ & $\sqrt{1}$ & $\sqrt{ }$ & $\sqrt{ }$ & $x$ & $100 \%$ \\
\hline 9 & key chain 1 & $\sqrt{ }$ & $\sqrt{ }$ & $\sqrt{ }$ & $\sqrt{ }$ & $\mathbf{X}$ & $\mathbf{X}$ & $\mathbf{X}$ & $\mathbf{X}$ & $\mathbf{X}$ & $\mathbf{X}$ & $50 \%$ \\
\hline 10 & key chain 2 & $\sqrt{ }$ & $\sqrt{ }$ & $\sqrt{ }$ & $\sqrt{ }$ & $\mathbf{X}$ & $\mathbf{X}$ & $\mathbf{X}$ & $\mathbf{X}$ & $\mathbf{X}$ & $\mathbf{X}$ & $50 \%$ \\
\hline 11 & key chain 3 & $\sqrt{ }$ & $\sqrt{ }$ & $\sqrt{ }$ & $\sqrt{ }$ & $\mathbf{X}$ & $\mathbf{X}$ & $\mathbf{X}$ & $\mathbf{X}$ & $\mathbf{X}$ & $\mathbf{X}$ & $50 \%$ \\
\hline 12 & key chain 4 & T & $\sqrt{ }$ & $\sqrt{ }$ & T & $\mathbf{X}$ & $\mathbf{X}$ & $\mathbf{X}$ & $\mathbf{X}$ & $\mathbf{X}$ & $\mathbf{X}$ & $50 \%$ \\
\hline
\end{tabular}

Dari hasil pengujian tabel 4.3 pembacaan tag RFID jenis $e$-KTP agar bekerja secara baik mampu terdeteksi kodenya dapat dilakukan dengan jarak maksimal $\leq 3,5 \mathrm{~cm}$, jarak tersebut tingkat keberhasilan terdeteksinya $100 \%$ antara Reader RFID ke e-KTP. jenis tag RFID jenis white card mampu bekerja dengan jarak $\leq 5 \mathrm{~cm}$ sehingga persentase keberhasilan perancangan untuk jenis tag ini $100 \%$. jenis key chain hanya mampu bekerja dengan jarak $\leq 2,5 \mathrm{~cm}$, key chain merupakan jarak operasi yang paling dekat dari ketiga jenis tag RFID.

Dari ketiga jenis tag RFID tersebut walaupun frekuensi kerjanya sama yaitu $13,56 \mathrm{MHz}$ jarak pembacaan dari tag ke Reader berbeda-beda dikarenakan desain antena dari masing-masing tag berbeda-beda sehingga mempengaruhi jarak operasi kerjanya.

\section{Pengujian Mengakses Locker}

Untuk mendaftar dan menghapus pengguna locker dibutuhkan satu buah $e$-KTP sebagai admin dan memanfaatkan memori eeprom pada arduino pro mini agar mempermudah menghapus, mendaftar dan menyeleksi pengaksesan antara penguna locker 1 dan locker 2 .

Kode-kode $e$-KTP yang telah didaftar pada memori eeprom arduino selanjutnya diuji sistem kerjanya apakah berjalan dengan baik atau tidak dan diberi pengujian dengan tag RFID dengan frekuensi $13.35 \mathrm{kHz}$ jenis lain.

Dari sample 1 buah $e$-KTP sebagai admin, 6 buah $e$-KTP sebagai calon pengguna dan 8 buah tag RFID jenis lain sebagai penguji sistem kerja locker. Maka hasil kombinasi 
seluruh tag RFID untuk mengakses locker menggunkan persamaan (2.8)

$$
\begin{aligned}
& C(12,2)=\frac{12 !}{2 !(12-2) !} \\
& C(12,2)=\frac{479001600}{2 !(12-2) !} \\
& C(12,2)=\frac{479001600}{7257600}=66 \text { Kombinasi }
\end{aligned}
$$

Dari persamaan kombinasi percobaan diatas didapat 66 percobaan untuk menguji pengaksesan locker, setelelah melakukan pengujian di Laboratorium Teknik Elektro dengan 66 kombinasi pengujian tersebut, hasil pengujiannya didapat bahwa sistem menghapus, mendaftar dan penyeleksian antara kode $e$-KTP locker 1 dan locker 2 pada memori eeprom arduino berhasil bekerja dengan baik. Data hasil pengujian dapat dilihat dilampiran 3. Dari 15 tag RFID yang berbeda- beda dan diuji dengan 66 kombinasi pengujian untuk pengaksesan locker artinya pengguna locker dapat diperbanyak lebih dari 2 pengguna locker dikarenakan sistem yang dirancang mampu menyeleksi kode-kode diantara 15 tag RFID tersebut dan sudah diuji juga dengan menambahkan pengguna locker diproram arduino yaitu sebanyak 15 pengguna locker

\section{KESIMPULAN}

Berdasarkan hasil pengujian dan pengamatan yang telah dilakukan pada sistem keamanan locker dengan pemanfaatkan teknologi radio frequency identification (RFID) pada e-KTP untuk pengamannya, maka dapat saya simpulkan sebagai berikut :

1. Setelah melakukan 66 kombinasi pengujian eeprom Arduino Pro Mini, sistem penyimpanan data masih stabil dan tidak bisa diganggu jika diberi akses dengan jenis tag RFID lain. Proses pengenalan data begitu sensitif sehingga perancangan alat keamanan ini lebih aman.

2. Alat ini sudah diuji mampu merekam lebih dari 2 pengguna locker yaitu sebanyak 15 pengguna locker.

3. Jarak baca efektif tag jenis key chain dengan tingkat keberhasilan $100 \%$ jarak bacanya $\leq 2,5 \mathrm{~cm}$ untuk pengguna $e$-KTP jarak baca efektif dengan tingkat keberhasilan $100 \%$ berjarak $\leq 3,5 \mathrm{~cm}$ dan jenis tag RFID white card dengan tingkat keberhasilan $100 \%$ jarak baca $\leq 5 \mathrm{~cm}$, tag white card merupakan jarak baca paling terjauh diantara $e$-KTP dan key chain sesuai dengan data sheet reader RFID RC522.

4. Ketiga jenis tag RFID tersebut setelah diuji jarak pembacaannya berbeda- beda dikarenakan desain antena dari masing-masing tag berbeda-beda sehingga mempengaruhi jarak operasi kerjanya.

\section{REFERENSI}

[1] Eko Budi Setiawan, 2015. "Perancangan Sistem Absensi Kehadiran Perkuliahan dengan Menggunakan Radio Frequency Identification (RFId)." Jurnal CoreIT, Vol.1, No.2.

[2]. Daniel Hunt, 2017. RFID A Guide To Radio Frequency Identification, John Wiley \& Sons Inc, New York.

[3]. Bobi Kurniawan, 2016. "Perbaikan Sistem Parkir Kendaraan Bermotor Di Lingkungan Universitas Komputer Indonesia
Dengan Menggunakan Rfid Dan Database." Majalah Ilmiah UNIKOM, Vol.12, No. 2.

[4]. Tadu Puasandi, 2014. "Sistem Akses Kontrol Kunci Elektrik Menggunakan Pembacaan E-Ktp” Studentjournal. Vol.1, No. 1.

[5]. Dedy Rahman Wijaya, 2014. "Middleware Architecture For National Electronic Id Card: The Case Of E-Ktp In Indonesia." Journal of Theoretical and Applied Information Technology. Vol.9, No. 3.

[6]. Peraturan Menteri Dalam Negeri, Nomor : 6 Tahun 2011 Tentang Spesifikasi Perangkat Keras, Perangkat Lunak Dan Blangko Ktp Berbasis Nik Secara Nasional, Jakarta.

[7] Sunfounder,

2016."'https://www.sunfounder.com/wiki/index.php?title= Mifare_RC522_Module_RFID_Reader.” Tanggal Akses 11 Juni 2016.

[8] Supriyono, 2010." Penerapan Aplikasi Rfid Dibidang Perpustakaan.” JMTE,Vol.2,No.2.

[9] Eko Saputro, 2016. "Rancang Bangun Pengaman Pintu Otomatis Menggunakan E-Ktp Berbasis Mikrokontroler Atmega328." Jurusan Teknik Elektro, Fakultas Teknik, Univeritas Sumatra Utara.

[10] Arduino,2016.

https://www.arduino.cc/en/Main/ArduinoBoardProMini. Tanggal akses 5 Maret 2016.

[11] Djoko Santoso, 2009. “Teori Dasar Rangkaian Listrik.” Lambang Media Tama, Yogakarta. 